\title{
Expression of the Ferrioxamine Receptor Gene of Erwinia amylovora CFBP 1430 During Pathogenesis
}

\author{
Alia Dellagi, Danièle Reis, Brigitte Vian, and Dominique Expert \\ Laboratoire de Pathologie Végétale, INRA / INA P-G, 16 rue Claude Bernard, F-75 231, Paris, France \\ Accepted 22 January 1999.
}

\begin{abstract}
Mutants of Erwinia amylovora CFBP 1430 lacking a functional high-affinity iron transport system mediated by desferrioxamine are impaired in their ability to initiate fire blight symptoms (A. Dellagi, M.-N. Brisset, J.-P. Paulin, and D. Expert. Mol. Plant-Microbe Interact. 11:734-742, 1998). In this study, a chromosomal transcriptional lac Z fusion was used to analyze the expression in planta of the E. amylovora ferrioxamine receptor gene foxR. LacZ activity produced by the strain harboring the fusion was highly induced in iron-restricted conditions and in inoculated apple leaf tissues. Microscopic observation revealed differential expression of this gene in relation to the localization and density of bacterial cells within the diseased tissue. Thus, the ability of bacterial cells to express their iron transport system in accordance with environmental conditions is likely important for disease evolution.
\end{abstract}

Erwinia amylovora is the enterobacterium that causes fire blight, a disease of Maloideae plants. Progressive necrosis and ooze production are the main symptoms appearing on infected tissues. Harpin and disease-specific proteins released by the Hrp secretion pathway and the exopolysaccharide amylovoran are essential for pathogenicity (Bogdanove et al. 1996; Gaudriault et al. 1997; Bogdanove et al. 1998; Bugert and Geider 1995). In addition, a high-affinity iron assimilation pathway mediated by desferrioxamine (DFO) has recently been shown to be involved in the virulence of E. amylovora CFBP 1430 (Dellagi et al. 1998). DFO E is the main siderophore of the DFO family produced by this bacterium (Feistner et al. 1993; Kachadourian et al. 1996). The ferric complex of this siderophore, ferrioxamine, crosses the bacterial outer membrane through a specific receptor called FoxR. The foxR gene is an iron-regulated monocistronic unit, as shown previously by Northern (RNA) blot analysis (Dellagi et al. 1998). Interestingly, DFO is not only critical for iron acquisition, but also can potentially interfere with the oxidative burst occurring in

Corresponding author: Dominique Expert; Telephone: (33) 01440817 06; E-mail: expert@inapg.inra.fr

Present address of Alia Dellagi: Scottish Crop Research Institute, Invergowrie, Dundee DD2 5DA, Scotland.

Nucleotide and/or amino acid sequence data are to be found at the GenBank/EMBL data base as accession number AJ223062. the early stage of the interaction between plant and bacteria by protecting the invading pathogen from being killed by the reactive oxygen species (Dellagi et al. 1998). The objective of this study was to determine if the induction of this iron assimilation pathway in iron-depleted medium also takes place during pathogenesis. Using a transcriptional lac fusion, we investigated the expression of the fox $R$ gene in infected apple leaves.

A plasmid harboring the foxR gene was mutagenized with the prophage $\mathrm{Mud} d 1734$, which can generate transcriptional fusions (Casthilo et al. 1984) and the fusion foxR9::lacZ selected to study fox $R$ expression. Its precise position was assessed by sequencing and found to be at 108 nucleotides from the end of the gene (foxR; GenBank/EMBL data bank, accession number AJ223062). This mutation was recombined into E. amylovora CFBP 1430 chromosome by marker exchange and the Fox ${ }^{-}$phenotype of the resulting strain was properly checked as described previously (Kachadourian et al. 1996). In order to avoid the abnormal iron deficiency effect leading to the reduced capability of the transport mutant to cause fire blight symptoms, a plasmid containing a fox $R$ wild-type allele, pAL2 (Dellagi et al. 1998), was introduced in trans in the foxR9::lac $Z$ harboring strain. The mutant strain containing the vector alone (pLA2917) was used as a control.

In order to assess the effect of iron availability on the expression of the fusion, bacterial cells were grown in LuriaBertani (LB) medium supplemented with either a strong $\mathrm{Fe}$ (III) chelator or ferric ions. Although LB medium is not starved of iron, we used it because usual iron-depleted media also display a low phosphate content leading to plasmid destabilization. The $\beta$-galactosidase activity of the cultures was measured as described previously (Miller 1972; Fig. 1A). In the absence of a functional copy of the fox $R$ gene, the fusion appeared to be derepressed and, even in the presence of plasmid pAL2, the fusion was expressed at a relatively high level. This suggests that, in LB, iron is not readily available to $E$. amylovora cells. The addition of $\mathrm{FeCl}_{3}$ to the medium only decreased the level of foxR $9:: l a c Z$ expression by twofold. On the other hand, the presence of EDDHA enhanced (7.5 times) the LacZ activity, showing the inducer effect of iron chelation on fox $R$ gene expression. The decline in LacZ expression observed for optical densities greater than 0.8 reveals that the fox $R$ gene transcription decreases as the internal iron content increases because of the release of DFO into the medium. To investigate the correlation between fox $R$ gene expression in 

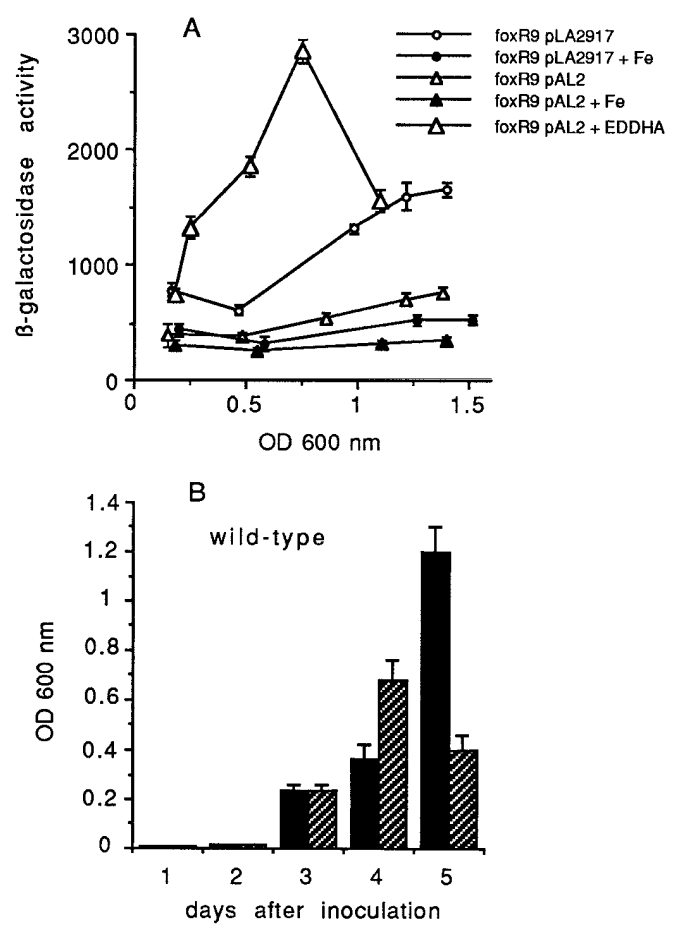

bacterial culture and in planta, the $\beta$-galactosidase activity produced by the bacteria in infected tissues was assessed. The engineered and parental strains were inoculated to young apple seedlings (Malus domestica cv. Evereste) in the glasshouse with an inoculum concentration of $10^{8} \mathrm{CFU} / \mathrm{ml}$, as described
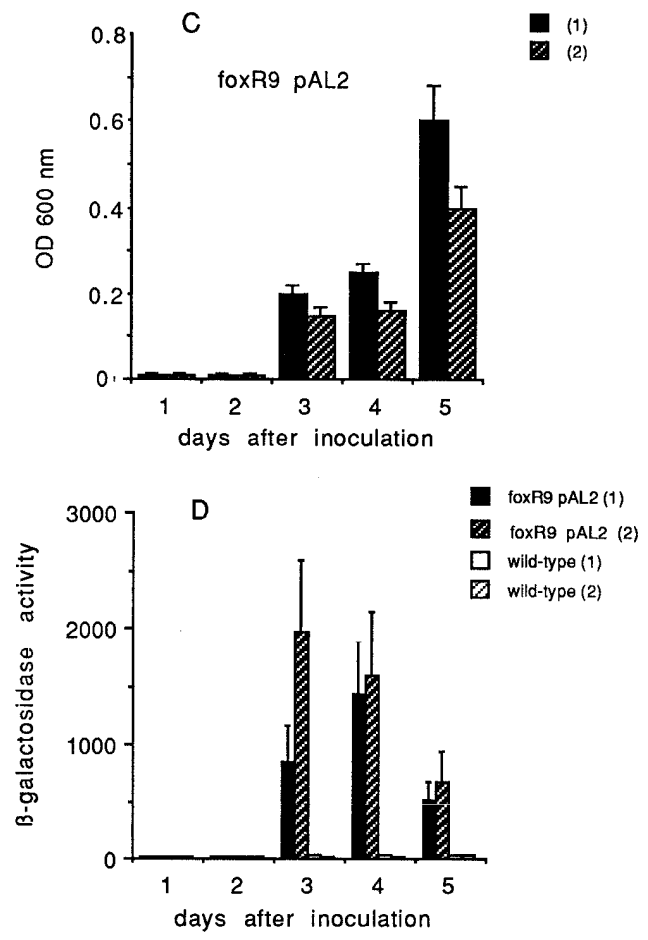

Fig. 1. Expression of the chromosomal foxR $9::$ lacZ fusion in Erwininia amylovora cells grown in (A) Luria-Bertani (LB) medium and (D) after inoculation onto apple seedlings. A, LB supplemented with $50 \mu \mathrm{M}$ EDDHA or $50 \mu \mathrm{M} \mathrm{FeCl}_{3}$ as indicated, to provide low and rich iron conditions, respectively. Experiment was performed in triplicate; standard deviations are shown. D, $\beta$-Galactosidase activity assayed in infected leaves, divided in three batches of five leaves, for 5 days after inoculation. Concurrent enumeration of bacterial populations was determined after plating on $\mathrm{L}$ agar medium in the presence and absence of appropriate antibiotics indicating plasmid stability. Correspondant optical densities at $600 \mathrm{~nm}$ were assessed as reported in $\mathbf{B}$ and $\mathbf{C}$. Two independent assays, (1) and (2), are shown. Control experiments correspond to plant tissues inoculated with the wild-type strain.
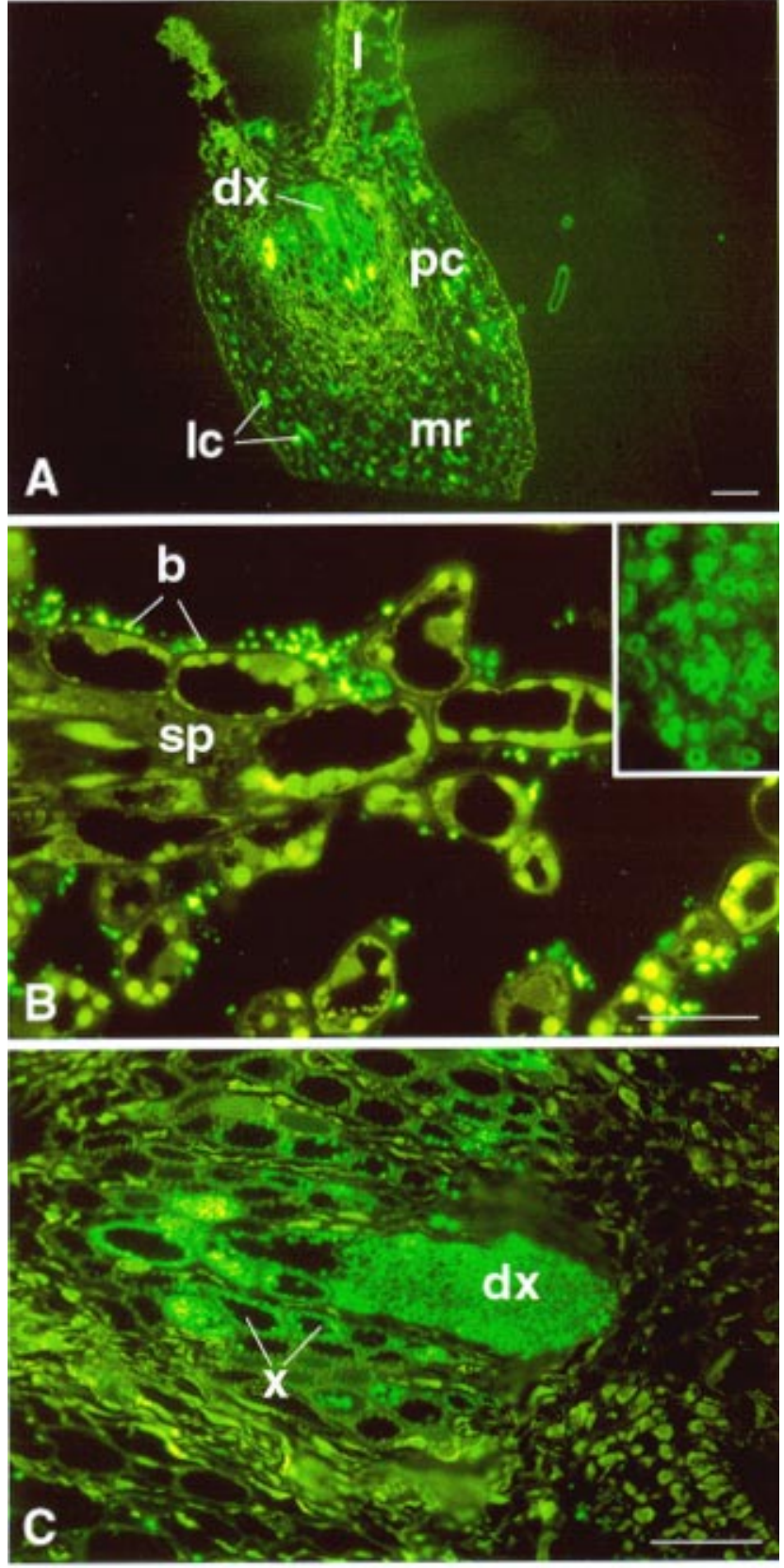

Fig. 2. In planta immunofluorescence detection of Erwininia amylovora cells harboring the fusion foxR9::lacZ and pAL2 with a rabbit antilipopolysaccharide (LPS) polyclonal serum and a fluorescein isothiocyanate (FITC) coupled anti-rabbit IgG conjugate. A, General view of a transverse section of a leaf. B, Detail of bacteria in intercellular spaces of the spongy parenchyma (sp) of the lamina. Bacteria (b) are in contact with the plant cell walls. Inset: high magnification showing labeling at the bacterial cell surface. $\mathbf{C}$, Detail of the midrib region with invasion of bacteria in tracheids (x) of the vein. A large, distorted xylem element (dx) is filled with bacteria. 1, lamina; lc, lysigenous cavity of the cortical parenchyma; mr, midrib; pc, cortical parenchyma; sp, spongy parenchyma; $B$ ar $=(\mathbf{A}) 100$ and $(\mathbf{B}$ and $\mathbf{C}) 20 \mu \mathrm{m}$. 
by Dellagi et al. (1998). Sterile, distilled water was used as control. Symptoms appeared in leaves from the fourth day and were sampled at days 1 to 5 following inoculation. Leaves were ground in a phosphate buffer supplemented with antioxidant agents (sodium phosphate buffer $[0.1 \mathrm{M}]$ with ascorbic acid $[10 \mathrm{mM}]$, reduced glutathione $[10 \mathrm{mM}]$, PVP10 [2\%], mannitol [1\%], $\mathrm{pH}$ 7). After filtration to remove plant debris, bacterial viable counts were performed (Fig. 1B and C) and the filtrate was treated as a standard sample for measuring $\beta$ galactosidase activity. The experiment was carried out in duplicate. Different levels of LacZ activity were obtained from leaves inoculated with the strain carrying the fusion while, as expected, no enzymatic activity was detected from the leaves inoculated with the parental strain (Fig. 1D) or water. The levels of foxR $9:$ lac $Z$ expression in the leaves varied with timecourse fluctuations, suggesting the existence of variations in iron availability during pathogenesis. This result indicates that the foxR gene is differentially regulated in vivo.

In order to further analyze the conditions of fox $R$ gene expression in infected leaves, a microscopic study was carried out. Apple leaves were harvested 5 days after inoculation. The leaves were chemically fixed for $2 \mathrm{~h}$ in $1.25 \%$ (vol/vol) glutaraldehyde in $0.15 \mathrm{M}$ sodium cacodylate buffer, $\mathrm{pH}$ 7.2. Histochemical staining of bacterial $\beta$-galactosidase activity was performed with X-Gal (5-bromo-4-chloro-3-indolyl- $\beta$-Dgalactopyranoside) as described by Vasse et al. (1995). Infected leaf pieces of interest were sampled from the necrotic regions and processed for microscopic embedding in LR White resin (Pelanne Instruments, Toulouse, France) as described elsewhere (Roland and Vian 1991). Light microscopical observations were performed on semithin sections of 0.5 to1 $\mu \mathrm{m}$.

To compare the tissue colonization by the wild-type strain and the strain harboring the fusion and plasmid pAL2, the bacteria were observed on sections with a specific antiserum that recognizes the lipopolysaccharide (LPS) of E. amylovora CFPB 1430 (Samson 1972), according to the classical twostep immunofluorescence procedure (Polak and van Noorden 1997). Similar observations were obtained for both strains. The infected leaf tissues contained a high population of bacteria. The bacteria were strongly fluorescent, which allowed us to localize them in the whole leaf, even at low magnification (as shown in Figure 2A), for the strain harboring the fusion. Controls performed without primary antibody were not fluorescent (data not shown). Three types of localization were observed: (i) in intercellular spaces of the mesophyll of leaf lamina, where they appeared to be linked to the plant cell walls (Fig. 2A and B); (ii) in the xylem of the midrib and es-
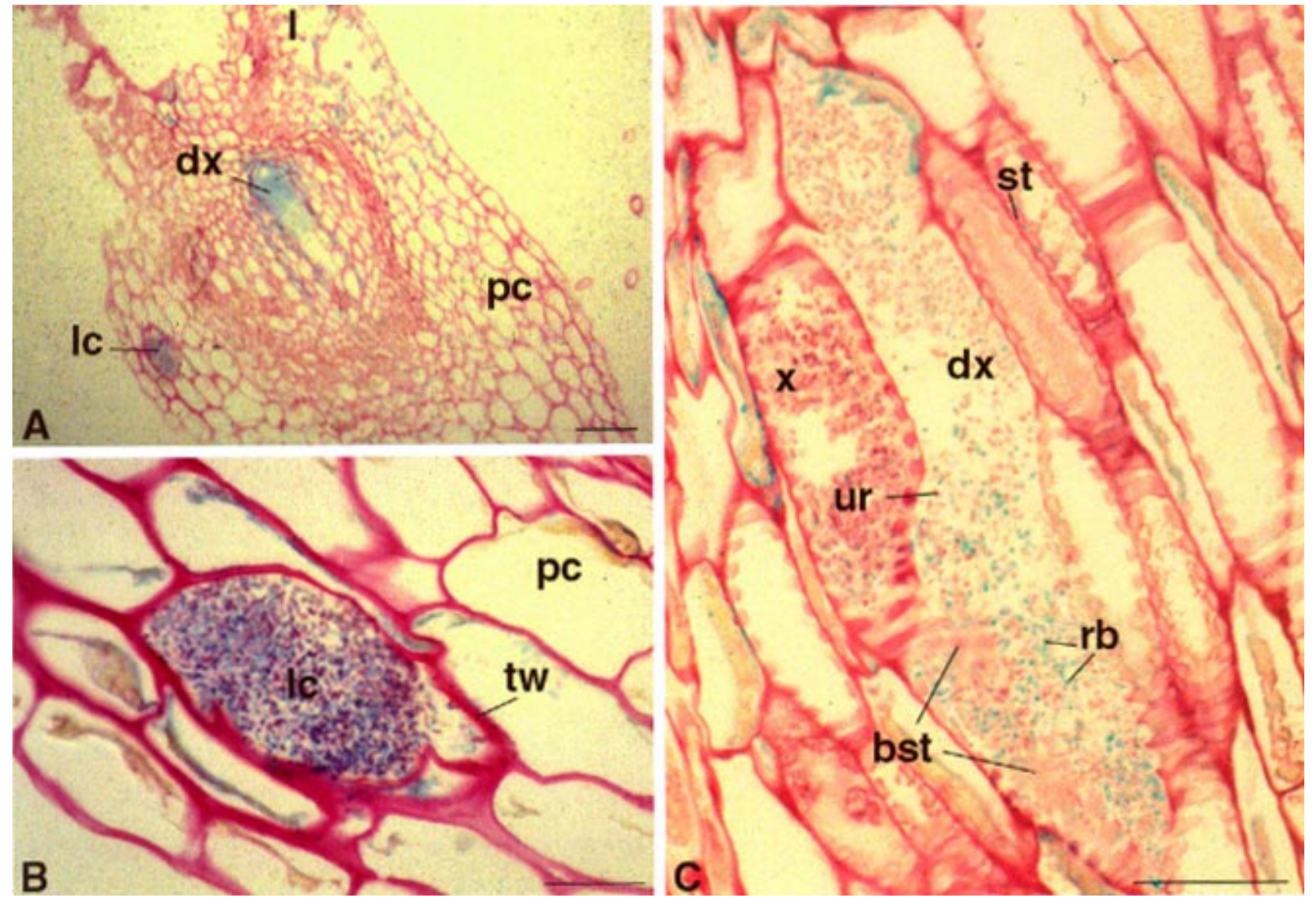

Fig. 3. In planta expression of the foxR9::lacZ fusion visualized by X-Gal (5-bromo-4-chloro-3-indolyl- $\beta$-D-galactopyranoside) staining. Sections poststained for $15 \mathrm{~s}$ with $0.1 \%$ aqueous fuchsin. A, General view showing expression in lysigenous cavities (lc) of cortical parenchyma (pc) and in distorted xylem element ( $\mathrm{dx})$ of midrib vein. B, Detail of a lysigenous cavity of the cortical parenchyma invaded with bacteria expressing different levels of $\beta$ galactosidase activity. It is surrounded by a thick cell wall (tw). C, Detail of the midrib vein showing some reactive bacteria (rb) expressing $\beta$ galactosidase in a distorted xylem element (dx). Conversely, bacteria present in a neighboring xylem element (x) are unreactive (ur). bst, broken secondary thickenings of xylem wall; 1, lamina; st, secondary thickenings. Bar $=(\mathbf{A}) 100$ and $(\mathbf{B}$ and $\mathbf{C}) 20 \mu \mathrm{m}$. 
pecially in distorted xylem elements (in the latter the bacteria were highly concentrated (Fig. 2A and C); and (iii) in lysigenous cavities likely derived from enlarged and damaged cortical parenchyma cells of the midrib (Goodman and White 1981). At higher magnification, the fluorescence was clearly localized at the periphery of the bacterial cells, thus confirming the specificity of the antiserum (Fig. 2B, inset). No fluorescence was seen in controls, in the absence of the specific antiserum (data not shown).

Among the different colonized compartments, the $\beta$-galactosidase activity was observed only at a high bacterial population (Fig. 3A). It was seen in some of the lysigenous cavities located in the outer cortical parenchyma of the midrib (Fig. $3 \mathrm{~A}$ and $\mathrm{B})$. The latter appeared as large cells, completely filled with both reactive and unreactive bacteria and generally surrounded by a cell wall thicker than that of neighboring cells. Bacteria expressing $\beta$-galactosidase activity were also seen in distorted xylem elements of the midrib vein (Fig. 3A and C). These distorted xylem elements also appeared as lysigenous cavities resulting from the collapse of a xylem tracheid in which remnants of secondary walls were still visible, as already described (Goodman and White 1981). Figure 3C clearly shows the occurrence of both reactive and unreactive bacteria in neighboring cells and even within a single cell. It is noteworthy that the $\beta$-galactosidase activity was not the same in all the bacterial cells, indicating a different metabolic status with respect to iron. Interestingly, Dellagi et al. (1998) have shown that DFO could be either protective or deleterious to bacterial cells, according to the concentration levels, thus suggesting an accurate control of its production in intercellular spaces of plant tissues. The fine regulation of the receptor gene supports this hypothesis.

These data show that the bacteria encounter iron-restricted conditions as they proliferate in extracellular compartments of leaf tissues. Since foxR mutants are nonpathogenic, it is likely that the ability of bacterial cells to express their iron transport system in accordance with environmental conditions is important for disease evolution.

\section{ACKNOWLEDGMENTS}

We thank J.-P. Paulin for providing us with the antiserum and apple seedlings, L. J. Hyman for proofreading the manuscript's English, and the anonymous reviewers for suggestions for improving the manuscript. A. D. was supported by INRA and Ministère Tunisien de l'Education. D. E. is a researcher from the CNRS. B. V. and D. R.. are Maitres de Conférence, University of Paris 6.

\section{LITERATURE CITED}

Bogdanove, A. J., Kim, J. F., Wei, Z., Kolchinsky, A. O., Charkowsky, A. O., Conlin, A. K., Collmer, A., and Beer, S. V. 1998. Homology and functional similarity of an hrp-linked pathogenicity locus, $d s p E F$, of Erwinia amylovora and the avirulence locus avrE of Pseudomonas syringae pathovar tomato. Proc. Natl. Acad. Sci. USA 95:1325-1330.

Bogdanove, A. J., Wei, Z.-M., Zhao, L., and Beer, S. V. 1996. Erwinia amylovora secretes harpin via a type III pathway and contains a homolog of yopN of Yersinia ssp. J. Bacteriol. 178:1720-1730.

Bugert, P., and Geider, K. 1995. Molecular analysis of the ams operon required for exopolysaccharide synthesis of Erwinia amylovora. Mol. Microbiol. 15:917-933.

Casthilo, B. A., Olfson, P., and Casadaban, M. J. 1984. Plasmid insertion mutagenesis and lac gene fusion with mini-Mu bacteriophage transposons. J. Bacteriol. 158:488-495.

Dellagi, A., Brisset, M.-N., Paulin, J.-P., and Expert, D. 1998. Dual role of desferrioxamine in Erwinia amylovora pathogenicity. Mol. PlantMicrobe Interact. 11:734-742.

Feistner, G. J., Stahl, D. C., and Gabrik, A. H. 1993. Proferrioxamine siderophores of Erwinia amylovora. A capillary liquid chromatographic / electrospray tandem mass spectrometry study. Org. Mass Spectrom. 28:163-175.

Goodman, R. N., and White, J. A. 1981. Xylem parenchyma plasmolysis and vessel wall disorientation caused by Erwinia amylovora. Phytopathology 71:844-852.

Gaudriault, S., Malandrin, L., Paulin, J.-P., and Barny, M.-A. 1997. DspA, an essential pathogenicity factor of Erwinia amylovora showing homology with AvrE of Pseudomonas syringae, is secreted via the Hrp secretion pathway in a DspB-dependent way. Mol. Microbiol. 26: 1057-1069.

Kachadourian, R., Dellagi, A., Laurent, J., Bricard, L., Kunesch, G., and Expert, D. 1996. Desferrioxamine-dependent iron transport in Erwinia amylovora CFBP 1430: Cloning of the gene encoding the ferrioxamine receptor FoxR. BioMetals 9:143-150.

Miller, J. F. 1972. Experiments in Molecular Genetics. Cold Spring Harbor Laboratory, Cold Spring Harbor, NY.

Polak, J. M., and van Noorden, S. 1997. Introduction to Immunocytochemistry. BIOS Scientific Pub., Oxford. pp. 1-141.

Roland, J.-C., and Vian, B. 1991. General preparation and staining of thin sections. Pages 1-66 in: Electron Microscopy of Plant Cells. J. M. Hall and C. Hower, eds. Academic Press, London.

Samson, R. 1972. Hétérogènéité des antigènes thermostables de surface chez Erwinia amylovora. Ann. Phytopathol. 4:157-163.

Vasse, J., Frey, P., and Trigalet, A. 1995. Microscopic studies of intercellular infection and protoxylem invasion of tomato roots by $\mathrm{Pseu}$ domonas solanacearum. Mol. Plant-Microbe Interact. 8:241-251. 